$$
\begin{gathered}
\text { 가정부문 에너지소비자의 라이프스타일 유형이 에너지절약행동에 } \\
\text { 미치는 영향 분석 } \\
\text { 임기추 } \\
\text { 에너지경제연구원 } \\
\text { (2013년 8월 1일 접수, 2013년 9월 16일 수정, 2013년 9월 16일 채택) }
\end{gathered}
$$

\title{
A Study on the Effects of Residential Energy Consumer's Lifestyle on Energy Conservation Behavior
}

\author{
Ki Choo, Lim \\ Korea Energy Economics Institute
}

(Received 1 August 2013, Revised 16 September 2013, Accepted 16 September 2013)

$$
\text { 요 약 }
$$

가정부문 에너지소비는 국가마다 중요한 에너지절약 목표로 간주되고 있다. 이는 에너지절약 측면뿐 만 아니라 소비자의 경제적 지출 측면에서도 매우 중요한 문제이다. 특히 가정부문 에너지소비는 소비 자의 라이프스타일과 매우 밀접한 관계가 있다. 그럼에도 불구하고 이에 대한 심도 있는 연구는 거의 없었다. 이에 따라 본고는 구조방정식 모형을 통해 에너지절약행동에 있어서 소비자의 라이프스타일 유형이 어떠한 영향을 미치는지를 살펴보았다. 연구결과, 생활만족형·절약의식형 및 절약실천형 라이 프스타일은 환경보전의식 및 환경보전의식과 정 $(+)$ 의 관계가 있으며, 경제적 비용인식과 환경보전의식 은 에너지절약의식과 정 $(+)$ 의 관계로 확인되었다. 그리고 에너지절약의식과 에너지절약행동은 정 $(+)$ 의 관계가 있는 것으로 분석되었다

주요어 : 가정부문, 에너지소비자, 라이프스타일, 에너지절약행동

\begin{abstract}
The residential energy consumption is intimately related with lifestyle of consumers. Therefore, this research suggests the mechanism for the effects of consumer lifestyle on consumer behavior. Specifically, the mediators are imposed of cost perception, propensity for environmental protection and energy conservation-conscious. Also, the lifestyle is composed of the over-consumption, life-centric, life-satisfaction, conservation- conscious and conservation-active type. In results, there are positive relationship between the life-satisfaction, conservation-conscious and conservation-active lifestyle and the propensity for environmental protection, cost perception. Both the cost perception and the propensity for environmental protection are positively related with the conservation- conscious. And positive relationship are appeared between the conservation-conscious and the energy conservation behavior.
\end{abstract}

Key words : residential energy consumer, lifestyle, energy conservation behavior

${ }^{\dagger}$ To whom corresponding should be addressed.

Korea Energy Economics Institute, Uiwang 437-713, Korea

Tel : 031-420-2295 E-mail : kclim@keei.re.kr

\author{
1. 서 론 \\ 현재 정부에서는 국가적인 에너지절약시책을 추진 \\ 하고 있지만, 국민의 생활수준 향상이나 라이프스타일
}


의 다양화에 따라 가정부문 에너지소비의 증가추세가 지속되고 있다. 선진국에서는 온실가스 배출 감축을 위한 대책의 일환으로 에너지절약이 새로운 핫이슈로 부각되었으며, 국가적 시책으로 논의되어 왔다 [12].

1973년 에너지위기 이후 많은 연구들이 에너지문 제에 대한 태도, 에너지절약태도, 에너지절약의식 및 에너지절약행동 간의 관계를 분석해 왔다. 일반적으 로 에너지절약행동은 에너지절약의식에 영향을 받는 것으로 설명되었다 [11,17,23-24]. 특히 Sardianou [22]는 그리스의 가정부문 에너지소비자를 대상으로 여러 변수들에 대한 라이프스타일의 차이점을 분석하 였다.

따라서 라이프스타일 파악에 의한 가정부문 에너 지소비자의 특성을 파악하고, 에너지소비에 영향을 주는 요인별로 에너지절약행동에 어떤 관계가 있는 지, 또한 에너지절약행동에 미치는 요인을 분석할 필 요가 있다. 가정부문 에너지소비와 관련된 인구통계 적 특성 및 심리적 요인을 고려한 라이프스타일 유형 도출이 보편화되고 있다. Seligman 등 [23]은 가족 중시형·편리추구형·개인중시형 및 절약중시형의 요인 을 도출하였다. 또 IEEJ [20]에서는 소비과잉형.생활 중시형·생활만족형·절약의식형 및 절약실천형의 유형 을 제시하였다. Barr 등 [14]은 절약형 기기 구매형. 습관적 절약형 및 재활용 실천형 등 요인을 도출하였 다.

본고에서는 설문조사를 통해 라이프스타일을 5 가 지 유형, 즉 소비과잉·생활중시·생활만족·절약의식 및 절약실천형을 구분하고, 경제적 비용인식과 환경보전 의식에 어떤 관계인지, 나아가 이들 변수가 에너지절 약의식에 어떤 관계인지, 마지막으로 이 변수가 에너 지절약행동에 어떤 영향을 미치는지를 분석하고자 하 였다.

\section{2. 이론적 배경 및 가설 설정}

\section{1 가정부문 에너지소비자}

가정부문 에너지소비란 주택 내에서 석유·전력 및 가스 등의 에너지를 사용하는 것이다. 구체적으로 말 하자면 가정 내에서 조명·난방.냉방.취사.위생·오락용 및 정보용 등의 용도로 사용되는 것을 가리킨다 [10]. 국내에서는 가정 내에서 가구 구성원들이 석탄·석유. 도시가스-전력·열 및 신재생에너지로 사용되는 에너
지를 가정부문 에너지소비로 집계하고 있다 [5].

본고에서는 가정부문 에너지소비에 포함되지 않지 만, 자가용 승용차를 거의 가정에서 보유하고 있기 때문에 에너지 소비활동과 관련성이 매우 밀접하므로 이를 포함하였다. 따라서 가정부문 에너지소비자는 동일한 가정 내에서 거주하며 생활하고 있는 가구주 를 비롯한 모든 가구 구성원으로, 가정에서 난방.온 수·취사·조명·가전기기용 및 승용차 등의 용도로 석 탄·석유·도시가스·전력·열 및 신재생에너지 등을 사 용하는 소비자로 정의한다.

\section{2 라이프스타일}

라이프스타일(lifestyle)은 가족·사회·문화 및 개인 의 준거집단 등에 영향을 받아 습득하는 경향이 있으 며 라이프스타일에 따라 소비행태가 크게 구별된다 [18]. 최근 들어 마케팅 및 소비자학 분야에서 라이프 스타일을 이용한 에너지소비관련 연구가 증가하고 있 다 $[15,25]$.

구체적으로 Seligman 등 [23]은 라이프스타일은 가족중시형·편리추구형·개인중시형 및 절약중시형의 4 개 요인으로 구분하였다. 또한 Barr 등 [14]은 에너 지와 관련한 라이프스타일을 절약형 기기 구매형·습 관적 절약형·재활용 실천형으로 구분하였다. 이용학 등 [7]은 2가지 라이프스타일 유형(생활중시형, 절약 의식형)이 경제적 비용인식과 환경보전의식에 어떤 관계인지, 나아가 에너지절약행동에 어떤 영향을 미 치는지를 분석한 바 있다. 특히 IEEJ [20]는 에너지 소비와 관련하여 소비과잉형·생활중시형·생활만족형. 절약의식형 및 절약실천형 등 5 가지 유형의 라이프스 타일을 제시하였다.

여기서, 소비과잉형은 가정 내 에너지소비가 많은 집단으로서 풍요로운 소비생활을 즐기는 집단이다. 이들에게 있어서 에너지절약은 큰 의미가 없다고 할 수 있다. 생활중시형은 비록 에너지소비가 많아진다 고 할지라도 자신의 생활을 위해 당연하다고 생각하 는 집단유형을 가리킨다. 생활만족형은 생활 속에서 조금은 에너지절약의 필요성을 느끼지만 현재 생활도 고려하는 유형이다. 절약의식형은 에너지절약정보에 관심은 많으나, 에너지절약을 어느 정도 실천하는 집 단을 의미한다. 절약실천형은 에너지절약에 매우 민 감하여 일상생활에서 매우 구체적으로 에너지절약을 실천하는 유형을 의미한다. 
2.3 에너지절약행동

먼저, 에너지절약행동(energy conservation behavior, energy saving behavior)이란 에너지소비를 줄이기 위해서 습관적으로 에너지절약을 실천하거나, 고효율 에너지사용기기를 선택적으로 구입하는 행위 로 정의한다 [17]. 우리나라의 가정부문 에너지절약 행동과 관련 국내 연구는 1980년대 이후 진행되었다. 즉, 에너지 문제가 심각해지면서 수요측면의 에너지 절약행동이 매우 중요한 주제로 등장하게 된 것이다. 백경미 [3]는 서울 주부를 대상으로 한 연구에서 연 령이 에너지절약태도, 에너지절약지식 및 에너지절약 행동에 영향을 주지 않았으며, 교육수준이 에너지절 약지식에, 소득이 에너지절약태도 및 에너지절약행동 에 영향을 미치는 것으로 나타났다. 또한 에너지절약 태도가 긍정적일수록, 에너지절약지식이 많을수록 에 너지절약행동의 수준은 더욱 높은 것으로 나타났다.

오세진 [6]은 서울 지역의 아파트 가구를 대상으로 에너지절약행동에 대한 태도요인, 성격요인(e.g., 내 적 통제, 책임감), 지식(e.g., 일반환경지식, 이슈지식, 행위전략지식), 환경에 대한 염려 및 행동의도 간의 인과관계를 살펴보았다. 분석결과, 환경에 대한 염려 는 환경관련 지식, 에너지절약행동 의도 및 실제 에 너지절약행동에 긍정적인 영향을 주는 것으로 나타났 다. 이러한 측면에서 볼 때, 에너지절약행동은 에너지 소비자의 각종 경제관련 요인 및 교육을 통한 환경관 련 지식 및 태도에 영향이 있음을 알 수 있다.

\subsection{1 경제적 비용인식}

Cameron [16]은 단열재 또는 이중창문 설치와 관 련하여 정부가 시설개선 금액의 약 $15 \%$ 를 지원해주 는 경우 전체 가구의 약 $3 \%$ 가 시설개선을 시도하였 다. 그런데 보조금이 늘어날수록 시설개선에 추가적 으로 각 가구도 점차 늘어났다. 이는 정부의 보조금 을 통한 가구의 경제적 이익이 에너지절약 개선행동 에 영향을 주고 있음을 보여주었다.

변순희 [4]는 분리수거 및 재활용 행동에 대한 금 전적 보상에 대한 인식이 환경친화적 행동에 영향을 미치는 것으로 분석하였다. 정유정 [9]의 연구에서도 경제적 비용인식이 높을수록 환경보전의식이 높은 것 으로 나타났다.

\subsection{2. 환경보전의식}

노채영 등 [2]은 환경의식이 높은 소비자는 자신의
소비가 사회, 환경, 복지에 영향을 준다고 인식하여 자신의 소비로 인해 초래되는 결과를 고려하여 제품 선택을 하는 경향이 있다고 한다. 따라서 소비자는 제품사용과 관련하여 편리함보다는 소비로 인해 나타 날 수 있는 환경오염을 고려하여 제품을 선택하고 있 음을 보여주고 있다.

Poortinga 등 [21]은 보다 구체적으로 환경에 대한 관심이 높을수록 에너지절약대책을 더 많이 수용하는 것으로 입증하였으며, 오세진 [6]은 소비자의 환경 관 련 염려는 에너지절약행동에 영향을 주는 것으로 파 악하였다.

\subsection{3 에너지절약의식}

Stern 등 [23]은 한 가정에 대한 에너지절약행동의 동기는 여러 가지 영향과 요인에서 발생하는데, 많은 연구들은 에너지절약에 대한 가치, 믿음 및 태도 등 의식 변수의 영향을 받는 것으로 분석하였다. Seligman 등 [23]은 에너지절약태도 변수를 사용해 대량의 전력소비를 설명했다. 연구결과 계량경제적 분석을 통해 에너지사용 행동방식과 밀접한 관련이 있는 신념과 행동 의도로, 이 에너지절약행동을 예상 할 수 있다는 점을 발견했다. Curtis 등 [17]은 에너 지절약 결정이 2 가지 태도 요인에 의해 영향을 받는 다는 사실을 알아냈다. 즉, 1) 개개인의 절약 활동이 중요하다는 믿음, 2) 에너지를 절약하기 위해서 자신 의 생활양식을 바꿀 의향 등이다.

한편 백경미 [3]는 에너지절약의식과 관련한 영향 을 미치는 주요 요인을 소득수준과 교육수준으로 파 악하였다. 소득수준이 높을수록 에너지절약의식 수준 이 낮으며, 교육수준이 높을수록 에너지절약의식이 높은 것으로 분석하였으며, 연령에 따른 에너지절약 의식은 차이가 없는 것으로 분석하였다.

\section{2-4. 연구가설 설정}

본고에서는 선행연구를 참조하여 가정부문 에너지 소비자가 특징적으로 갖고 있는 라이프스타일의 유형 별로 경제적 비용인식과 환경보전의식에 영향을 미치 는지, 또 이들 변수가 에너지절약의식에 어느 관계인 지 파악해 보고자 한다. 또한 이를 바탕으로 가정부 문 에너지소비자의 에너지절약행동에 미치는 영향을 파악하기 위해서 각 연구가설을 설정하였다. 
Table 1. Research hypothesis

\begin{tabular}{|c|c|}
\hline 가설 & 내용 \\
\hline $1-1$ & 소비과잉형 라이프스타일은 경제적 비용인식에 긍정적인 영향을 미칠 것이다. \\
\hline $1-2$ & 생활중시형 라이프스타일은 경제적 비용인식에 긍정적인 영향을 미칠 것이다. \\
\hline $1-3$ & 생활만족형 라이프스타일은 경제적 비용인식에 긍정적인 영향을 미칠 것이다. \\
\hline $1-4$ & 절약의식형 라이프스타일은 경제적 비용인식에 긍정적인 영향을 미칠 것이다. \\
\hline $1-5$ & 절약실천형 라이프스타일은 경제적 비용인식에 긍정적인 영향을 미칠 것이다. \\
\hline $2-1$ & 소비과잉형 라이프스타일은 환경보전의식에 긍정적인 영향을 미칠 것이다. \\
\hline $2-2$ & 생활중시형 라이프스타일은 환경보전의식에 긍정적인 영향을 미칠 것이다. \\
\hline $2-3$ & 생활만족형 라이프스타일은 환경보전의식에 긍정적인 영향을 미칠 것이다. \\
\hline $2-4$ & 절약의식형 라이프스타일은 환경보전의식에 긍정적인 영향을 미칠 것이다. \\
\hline $2-5$ & 절약실천형 라이프스타일은 환경보전의식에 긍정적인 영향을 미칠 것이다. \\
\hline $3-1$ & 경제적 비용인식은 환경보전의식에 긍정적인 영향을 미칠 것이다. \\
\hline $4-1$ & 경제적 비용인식은 에너지절약의식에 긍정적인 영향을 미칠 것이다. \\
\hline $4-2$ & 환경보전의식은 에너지절약의식에 긍정적인 영향을 미칠 것이다. \\
\hline $5-1$ & 에너지절약의식은 일반적 에너지절약행동에 긍정적인 영향을 미칠 것이다. \\
\hline $5-2$ & 에너지절약의식은 에너지절약형 기기의 선택 행동에 긍정적인 영향을 미칠 것이다. \\
\hline $5-3$ & 에너지절약의식은 에너지사용기기 사용의 자제 행동에 긍정적인 영향을 미칠 것이다. \\
\hline
\end{tabular}

*자료: 임기추(2009)에서 일부가설 수정

\section{3. 자료 수집 및 결과분석}

\section{1 조작적 정의 및 측정변수}

라이프스타일 변수는 IEEJ [20]에서 도출한 명칭 을 사용하여 소비과잉형·생활중시형·생활만족형·절약 의식형 및 절약실천형 등으로 구분하였다. 측정 기준 항목은 에너지소비, 에너지절약의식, 에너지절약 실 천, 생활비 정도, 전기요금, 에너지절약 방법, 에너지 절약 광고의 관심도, 일반소비생활, 환경보전, 기타 (가치관 등) 등 10 가지 개념을 적용하여 5점 등간척 도로 설정하였다(1점=부정적, 5점=긍정적).

경제적 비용인식은 가정에서의 에너지비용에 대해 심각하게 인식하는 정도를 파악할 수 있도록 난방 가 동시 연료비 인식, 에어컨 등 가전제품 이용시 전기 요금 인식, 온수사용시 비용 인식, 자가용 승용차의 연비나 연료비 인식 등 5 개 문항의 5 점 등간척도로 구성되어 있다(1점=적음, 5점=많음).

환경보전의식은 가정에서 에너지소비로 인해 환경 오염에 미치는 심각성의 인식 정도를 알기 위해 난방 용 연료 사용으로 인한 환경오염문제, 에어컨 등의
가전제품 이용을 위한 발전과정의 환경오염문제, 자 가용 승용차 이용에 따른 대기오염문제 등 3 개 문항 의 5 점 등간척도로 구성되어 있다(1점=낮음, 5 점=높 음).

에너지절약의식은 가정에서 에너지소비와 관련한 에너지절약문제에 대한 관심과 에너지절약 실천의 중 요성 및 필요성을 인식하고 있는 정도를 조사하기 위 해 5 개 문항의 5 점 등간척도로 설정되어 있다(1점= 낮음, 5점=높음).

에너지절약행동에 관한 문항은 먼저 일반적 에너 지절약행동 요인으로 외출시 소등여부, 에어컨 및 가 전제품 플러그 뽑기, 냉장고 내 보관물량의 적정상태 유지, 난방가동 중 불필요시 스위치 관리 등 5 개 문 항으로 구성되어 있다. 또한 에너지절약형 기기의 선 택 행동요인은 에너지소비효율 등급이 높은 에너지절 약형 조명등, 에어컨, 냉장고, TV 및 승용차 등을 구 입하는 5 개 문항과 그리고, 에너지사용기기 이용의 자제 행동요인은 냉방.난방 사용시간이나 사용강도의 자제, $\mathrm{TV}$ 시청 및 승용차 이용자제 등 5 개 문항의 5 점 등간척도로 측정하였다(1점=부정적, 5 점=긍정적). 
끝으로 에너지소비자의 인구통계적 특성은 성별, 연령, 교육수준, 가구 월평균소득, 직업, 주택형태, 주 택 사용면적, 가족수 및 가족관계 등 9개 항목으로 파악하였다 [8].

\section{2 자료수집 및 표본의 특성}

본고에서는 서울 지역 가정부문 에너지소비자를 대상으로 2009년 3월 19일부터 4월 6일까지 시청 중 심의 동서남북으로 나누어 150 부씩 임의표본을 할당 추출하여 총 600 부의 설문지를 직접 방문 면접방식 으로 조사하였다. 실제 조사대상자는 서울 지역에 거 주하고 있는 가구 중에서 가구당 20 세 이상의 가구 구성원 1 인으로 한정하였다. 설문조사 유효 응답자는 총 521가구이다 [8].

응답자의 특성을 보면, 성별로 여성 $50.1 \%$, 남성 $49.9 \%$ 로 비슷한 분포이며, 연령별로 40 대와 50 대 이 상이 각각 $27.1 \%, 27.4 \%$ 로 비슷하며, 20 대 $24.0 \%$, 30 대 $21.5 \%$ 순으로 나타났다. 교육수준의 경우 대졸 이상이 $42.0 \%$ 로 다소 많았고, 전문대졸 $31.5 \%$, 고졸 이하가 $26.5 \%$ 로 나타났다. 가구 월평균소득은 300 400 만원 미만이 $26.9 \%$ 로 가장 많았으며, 200 300 만원과 200 만원 미만이 각각 $23.8 \%, 21.5 \%, 400$ 500 만원이 $21.1 \%$ 로 나타났다.

\section{3 변수의 신뢰성 및 타당성 검증}

각 측정변수의 신뢰성은 Cronbach's a 계수로 검정 하였다. 신뢰성 분석결과, 모든 연구 개념의 신뢰도 (Cronbach's a)가 0.60을 넘었다. 일반적으로 a값이 0.6 이상이면 사회과학 조사연구 설문의 신뢰성이 충 분히 확보되었다고 할 수 있다 $[19,1]$. 즉, 각 변수는 선행연구를 토대로 할 때, 수용가능한 내적 일관성이 있다고 할 수 있다.

아울러 측정변수의 타당성 검증을 위해 주성분 요 인분석(principal components factor analysis)을 실시 하였다. 도출된 요인적재치가 모두 0.5 이상, 고유값 (eigenvalue)은 1 이상이어서 유의한 것으로 나타났 다 [13]. 특히, 라이프스타일 변수의 경우에도 요인적 재치(factor loading)가 모두 0.5 이상, 고유값 (eigenvalue)이 1 이상의 요인으로 유형화하였는데, 모두 유의한 것으로 나타났다 [13].

가정부문 에너지소비자에 대한 라이프스타일 변수 의 요인분석 결과 부적합한 문항을 제외하고 소비과
Table 2. Description of demographic characteristics

\begin{tabular}{c|c|c|c}
\hline 구분 & 항목 & 빈도(가구) & 백분율(\%) \\
\hline \hline \multirow{2}{*}{ 성별 } & 남성 & 260 & 49.9 \\
& 여성 & 261 & 50.1 \\
\hline \multirow{3}{*}{ 연령 } & 20 대 & 125 & 24.0 \\
& 30 대 & 112 & 21.5 \\
& 40대 & 143 & 27.4 \\
& 50대 이상 & 141 & 27.1 \\
\hline \multirow{2}{*}{ 교육수 } & 고졸 이하 & 138 & 26.5 \\
준 & 전문대졸 & 164 & 31.5 \\
& 대졸 이상 & 219 & 42.0 \\
\hline \multirow{3}{*}{ 월평균 } & 200만원 미만 & 112 & 21.5 \\
소득 & 300만원 미만 & 124 & 23.8 \\
& 400 만원 미만 & 140 & 26.9 \\
& 500 만원 미만 & 110 & 21.1 \\
& 500 만원 이상 & 35 & 6.7 \\
\hline
\end{tabular}

Table 3. Summary of reliability and validity

\begin{tabular}{|c|c|c|c|c|}
\hline 구분 & 요인 & $\begin{array}{c}\text { 요인 } \\
\text { 적재치 }\end{array}$ & 고유치 & $\begin{array}{l}\text { 분산 } \\
\text { 비율 }\end{array}$ \\
\hline \multirow{5}{*}{$\begin{array}{l}\text { 라이프 } \\
\text { 스타일 }\end{array}$} & 소비과잉형 & 0.590 이상 & 4.445 & 11.398 \\
\hline & 생활중시형 & 0.556 이상 & 5.119 & 24.525 \\
\hline & 생활만족형 & 0.583 이상 & 4.950 & 37.216 \\
\hline & 절약의식형 & 0.560 이상 & 4.799 & 49.522 \\
\hline & 절약실천형 & 0.467 이상 & 3.239 & 57.826 \\
\hline $\begin{array}{c}\text { 경제적 } \\
\text { 비용인식 }\end{array}$ & - & 0.497 이상 & 2.119 & 57.371 \\
\hline $\begin{array}{c}\text { 환경 } \\
\text { 보전의식 }\end{array}$ & - & 0.800 이상 & 2.031 & 67.707 \\
\hline $\begin{array}{c}\text { 에너지 } \\
\text { 절약의식 }\end{array}$ & - & 0.643 이상 & 2.460 & 59.209 \\
\hline
\end{tabular}

잉형(요인 1) 라이프스타일에 6개 문항, 생활중시형 (요인 2) 라이프스타일에 7개 문항, 생활만족형(요인 3) 라이프스타일에 9개 문항, 절약의식형(요인 4) 라 이프스타일에 8개 문항, 그리고 절약실천형(요인 5) 라이프스타일에 9 개 문항 등으로 묶여 총 5 개의 요인 으로 구분되었다 [8].

\section{4 연구가설 검증}

\subsection{1 모형의 적합도} 라이프스타일의 유형, 즉 소비과잉형·생활중시형. 
Table 4. Fit of structural equation models

\begin{tabular}{c|c|c|c|c|c|c|c}
\hline 지수 & $\chi^{2}$ & RMR & RMSEA & NFI & NNFI & CFI & GFI \\
\hline \hline 적합도 & 62.914 & 0.043 & 0.047 & 0.902 & 0.907 & 0.922 & 0.876 \\
\hline
\end{tabular}

생활만족형·절약의식형 및 절약실천형의 유형과 경제 적 비용인식과 환경보전의식, 그리고 에너지절약의식 과 에너지절약행동 간의 관계를 파악하기 위하여 공 분산 구조분석을 활용하여 연구모형의 적합도를 평가 하였다.

모형의 적합도를 보면 $\chi^{2}$ (카이자승 통계량)의 수치 는 유의하게 나타났으며, RMR(평균제곱잔차제곱근) 과 RMSEA(근사오차제곱평균제곱근)가 0.05 이하로 기준치와 부합하고, $\mathrm{NFI}$ (준적합지수), $\mathrm{NNFI(비표준}$ 적합지수), $\mathrm{CFI}$ (비교적합지수)는 등이 전반적으로 0.9 이상이며, $\mathrm{GFI}($ 기초적합지수)는 0.9 에 근접하고 $\mathrm{AGFI}$ (조정적합지수)가 0.8 을 넘어 모형의 적합도가 검증되었음을 알 수 있다 [1]. 즉, 분석된 모형의 전 반적인 구조방정식 모형의 적합도는 $\chi^{2}$ 값과 주어진 모형이 자료를 잘 설명해주고 있는지를 나타내는 지 수 즉, 절대적합지수 $(\mathrm{GFI}, \mathrm{RMR}, \mathrm{RMSEA})$ 와 증분적 합지수(NFI, NNFI, CFI, AGFI) 등 여러 가지 기준 에서 볼 때 전반적으로 비교적 자료를 잘 설명하는 모형으로 평가할 수 있다.

\subsection{2 연구가설 검증}

본고에서 가정부문 에너지소비자에 대한 라이프스 타일 유형을 도출하고, 이러한 라이프스타일 유형이 경제적 비용인식과 환경보전의식에 영향을 미치는지, 또 이들 변수가 에너지절약의식과 어떤 관계인지 파 악하였다. 또한 이를 바탕으로 가정부문 에너지소비 자의 에너지절약행동에 미치는 영향을 파악하고자 하 였다. 이를 위해 본고에서는 타당성과 신뢰성 검증 및 공분산 구조분석 등을 실시하여 가설을 검증하였 다.

첫째, 가정부문 에너지소비자의 생활만족형·절약의 식형 및 절약실천형 라이프스타일 유형은 경제적 비 용인식에 긍정적인 영향을 미쳤다. 반면 소비과잉형. 생활중시형의 라이프스타일 유형도 경제적 비용인식 에 어떠한 영향을 미치지 않는 것으로 나타났다. 둘 째, 가정부문 에너지소비자의 생활만족형·절약의식형 및 절약실천형 라이프스타일 유형은 환경보전의식에 긍정적인 영향을 미쳤다. 이와 달리 소비과잉형 라이

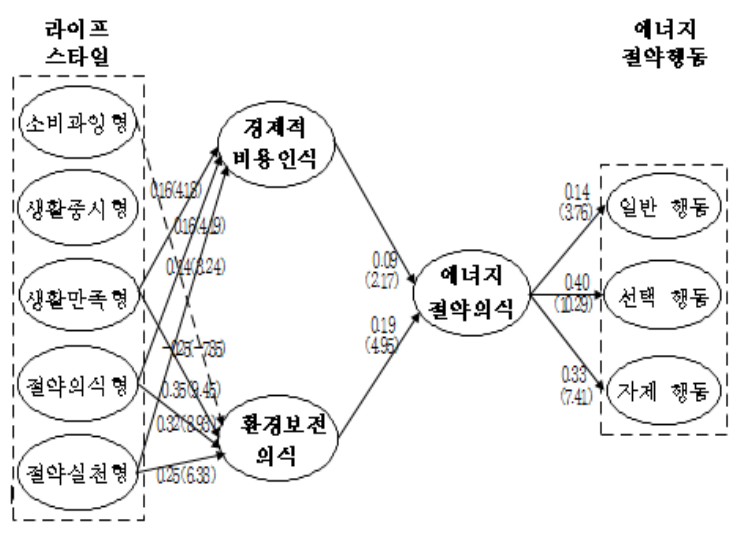

주: 1)실선은 긍정적(+), 점선은 부정적(-) 관계임.

2)수치는 공분산 구조모형의 경로계수(C.R. 값)임.

Fig. 1. Results of hypothesis

프스타일 유형은 환경보전의식에 부정적인 영향을 미 치며, 반면 생활중시형 라이프스타일 유형은 환경보 전의식에 어떠한 영향도 미치지 않는 것으로 나타났 다.

셋째, 가정부문 에너지소비자의 경제적 비용인식은 환경보전의식에 긍정적인 영향을 미치지 않는 것으로 나타났다. 넷째, 가정부문 에너지소비자의 경제적 비 용인식과 환경보전의식은 에너지절약의식에 긍정적 인 영향을 미쳤다. 다섯째, 가정부문 에너지소비자의 에너지절약의식은 일반 행동·선택 행동·자제 행동에 긍정적인 영향을 미쳤다.

이와 같이 가정부문 에너지소비자의 라이프스타일 유형이 경제적 비용인식과 환경보전의식에 영향을 미 치고, 또 이들 변수가 에너지절약의식에 영향을 미치 는 것으로 파악되었다. 또한 에너지절약의식은 에너 지절약행동에도 영향을 미치는 것으로 분석되었다. 따라서 가설 1-3, 1-4, 1-5, 2-3, 2-4, 2-5, 4-1, 4-2, $5-1,5-2,5-3$ 은 채택되었다.

\section{4. 결론 및 시사점}

연구결과는 에너지절약과 관련한 연구로부터 현상 을 보다 명확히 설명하고 있다는 점에서 기존의 연구 
에 비해 보다 진일보된 연구라 할 수 있다. 기존의 연 구에서 다루고 있지 않은 에너지소비자의 라이프스타 일을 분석한 점이 가장 큰 기여라 할 수 있다.

첫째, 가정부문 에너지소비자의 라이프스타일은 소 비과잉형·생활중시형·생활만족형. 절약의식형 및 절 약실천형으로 구분되었다. 이러한 라이프스타일 유형 과 에너지절약행동 간의 관계를 보면, 생활만족형·절 약의식형 및 절약실천형 라이프스타일이 에너지절약 행동에 긍정적인 영향을 미는 것으로 분석되고 있다. 따라서 생활만족형·절약의식형 및 절약실천형 라이프 스타일을 가진 에너지소비자를 ‘관심집단’으로 설정하 고, 종전과 같이 에너지절약에 관한 교육과 홍보 및 에너지절약 정보제공을 지속하는 유지전략이 중요하 다고 하겠다.

둘째, 생활중시형 라이프스타일을 가진 에너지소비 자가 단기적으로 에너지절약행동 수준을 높이기 위한 효과적인 목표가 될 수 있다. 생활중시형 라이프스타 일이 에너지절약행동에 영향을 미치지 않는 것으로 분석되고 있다. 따라서 이러한 생활중시형 라이프스 타일을 가진 에너지소비자는 ‘주의집단'으로 설정하 고, 에너지절약 및 환경보전에 관한 교육이나 홍보를 적극적으로 추진하는 실효성있는 전략이 강구되어야 하겠다.

셋째, 소비과잉형 라이프스타일을 가진 에너지소비 자는 에너지절약행동에 부정적이거나 영향을 미치지 않는 것으로 분석되고 있다. 따라서 소비과잉형 라이 프스타일의 에너지소비자를'집중적 강화집단'으로 규 정해, 에너지절약 교육이나 홍보를 집중적으로 강화 하는 전략이 마련되어야 할 것이다.

향후 연구과제로 가정부문 에너지소비자에 대한 에너지절약 정보제공과 지식수준을 통제하고 소비자 자신의 라이프스타일이 에너지절약행동에 미치는 영 향을 분석한다면 더욱 의미가 있으리라 생각된다. 다 음으로 라이프스타일 유형에 의거해 관심집단.주의집 단 및 집중적 강화집단으로 규정함에 따른 차별적인 교육 및 홍보전략이 필요한데, 이들 집단의 특성이 무엇인지 구명할 수 있는 추가적인 분석이 진행되어 야 할 것이다.

\section{참고문헌}

1. 김계수, New Amos 18.0 구조방정식모형 분석, 한 나래출판사, 2010.
2. 노채영, 신효식, 조혜정, 환경문제에 대한 소비자 의식과 행동에 관한 연구, 한국가정관리학회지 9(2), pp. 49-62, 1991.

3. 백경미, 소비자의 에너지소비절약행동 및 관련 변인에 관한 연구, 한국가정관리학회지 5(2), pp. 29-44, 1987.

4. 변순희, 도시 취업주부의 라이프스타일 및 환경 친화적 행동, 숙명여자대학교 대학원 박사학위 논 문, 2003.

5. 에너지경제연구원, 산업자원부, 에너지통계연보, 2001.

6. 오세진, 에너지절약행동을 위한 선행요인들의 효 과 검증, 한국심리학회, 사회문제 7(1), pp. 37-62, 2001.

7. 이용학, 임기추, 가정부분 에너지 소비자의 라이 프스타일이 에너지 절약행동에 미치는 영향, 상품 학연구 28(4), pp. 1-10, 2010.

8. 임기추, 가정부문 에너지소비자의 라이프스타일 이 에너지절약행동에 미치는 영향, 수원대학교 대 학원 박사학위 논문, 2009.

9. 정유정, 소비자 가치지향과 의복추구혜택에 따른 환경친화적 의류구매행동 연구, 경성대학교 대학 원 박사학위 논문, 2007.

10. 日本建築學會, 日本住宅內エネルギ?消費實態 全國調查, 2003.

11. 日本 環境省, 環境稅課稅に伴う行動變化に關 するアンケ?ト調查の結果, 2005.

12. Abrahamse, W., L. Steg, C. Vlek, \& T. Rothengatter, The Effect of Tailored Information, Goal Setting, and Tailored Feedback on Household Energy Use, Energy-Related Behaviors, and Behavioral Antecedents, Journal of Environmental Psychology 27, pp. 1-12, 2007.

13. Baggozzi, R. P., \& Y. Yi, On the Evaluation of Structural Equation Model, Journal of the Academy of Marketing Science 16, pp. 74-94, 1998.

14. Barr, S., A. W. Gilg, \& N. Ford, The Household Energy Gap: Examining the Divide between Habitual - and Purchase - Related Conservation Behaviors, Energy Policy 33, pp. 1425-1444, 2005. 
15. Bin, S., \& H. Dowlatabadi, Consumer Lifestyle Approach to US Energy Use and the Related CO2 Emission, Energy Policy 33, pp. 247-257, 2005.

16. Cameron, T., A Nested Logit Model of Energy Conservation Activities by Owners of Existing Single Family Dwellings, Review of Economics and Statistics 2, pp. 205-211, 1985.

17. Curtis, F., P. Simpson-Housley, \& S. Drever, Household Energy Conservation, Energy Policy 12(4), pp. 452-456, 1984.

18. Engel, J. F., Blackwell, R. D., \& Kollat, D. T., Consumer Behaviour, 4th ed. The Dryden Press, 1990.

19. Hair, Jr. J. F., R. E. Anderson, R. L. Tatham, \& W. C. Black, Multivariate Data Analysis. 5th ed, Prentice Hall, 1998.

20. IEEJ(Institute of Energy Economics, Japan, Energy Conservation and Lifestyles, 1995.

21. Poortinga, W., L. Steg, C. Vleg, \& G. Wiesma, Household Preferences for Energy-Saving Measures: A Conjoint Analysis, Journal of Economic Psychology 24(1), pp. 49-64, 2003.

22. Sardianou, E., Household Energy Conservation Patterns: Evidence from Greece, Ph.D. Dissertation. Harokopio University. Greece, 2005.

23. Seligman, C., Kriss, M., Darley, J. M., Fazi, R. H., Becher, L. J., \& Pryor, J. B., Predicting Summer Energy Consumption from Homeowner's Attitudes, Journal of Applied Social Psychology 9, pp. 70-90, 1979.

24. Stern, P., \& G. Gardner, Psychological Research and Energy Policy, American Psychologist 36(4), pp. 329-342, 1981.

25. Wei, Y. M., L. C. Liu, Y., Fan, \& G. Wu., The Impact of Lifestyle on Energy Use and CO2 Emission: An Empirical Analysis of China's Residents, Energy Policy 35, pp. 247-257, 2007. 